\title{
Utilizing a Human Rights Perspective to Train Therapists in Sexuality and Sexual Wellness
}

\begin{abstract}
By Shannon B. Dermer ${ }^{*}$, Shea M. Dunham ${ }^{ \pm} \&$ Molli E. Mercer ${ }^{+}$
Psychological associations require their trainees and professionals to work with diverse issues and diverse clientele, including sexual issues and sexual and gender minorities. While these organizations have been clear on their stance on non-discrimination toward sexual and gender minorities, research has demonstrated that most psychologists are not well trained on sexuality in general, even though educators and trainees believe sexuality is an important topic. Sexuality is a core aspect of human development across the lifespan. Although sexuality may be expressed differently across cultures, sexuality is a part of overall health and wellness for everyone. Sexuality is a broad concept that can include all types of sexual behaviors, sexual and gender orientation, sexual relationships, sexual pleasure, intimacy, attachment, and reproduction. It may be helpful for psychology to adopt a human rights perspective in their sexuality training. This perspective frames sexual rights as human rights and utilizes a sexual health and wellness framework. Utilizing this perspective, psychologists can focus on sexual citizenship from a global, rights-based, positive, and sexual wellness.
\end{abstract}

Keywords: Human Rights, Pedagogy, Psychology, Sexual Rights, Sexual Wellness.

\section{Introduction}

Optimal health and wellness incorporate aspects of the body, mind, and spirit - including one's sexual health and wellbeing. Sexual health encompasses (a) physical, psychological, and social well-being; (b) the possibility of engaging in safe, pleasurable sexual experiences, and; (c) being unrestricted by sexual coercion, sexual discrimination, or violence (The World Health Organization [WHO] 2015). Several international organizations have been at the forefront of advocating for sexual health and associated sexual rights. For instance, The World Association for Sexual Health (WAS) has emphasized sexual health as requisite to peoples' attainment of overall wellness and well-being (2014). The World Health Organization (WHO) has been advocating for sexual health since 1970s and embraces a definition of healthy sexuality that includes a multiplicity of sexual behaviors and expression (WHO 2015). These international sexual rights advocates conceptualize the expression of sexuality as an individual right fostering quality of life, creating equitable social interactions, and enhancing

\footnotetext{
"Dean, College of Education, Governors State University, USA.

${ }^{ \pm}$Associate Professor, North Carolina A\&T State University, USA.

${ }^{+}$Assistant Professor, Florida Gulf Coast University, USA.
} 
individual and social responsibility - all of which promote the probability of peace in a society (WAS 2014).

The WAS is an international organization representing sexological organizations worldwide and has been a vanguard of sexual rights advocacy since 1978 (known then as the World Association for Sexology). In their advocacy for sexual health, this organization created a declaration outlining sixteen sexual rights (e.g. the right to equality and nondiscrimination; the right to the highest attainable standard of sexual health, with the possibility of pleasurable, satisfying, and safe sexual experiences; the right to be free from all forms of violence and coercion) (WAS 2014). They are part of a growing movement that steadfastly view sexual rights as human rights (Miller et al. 2015, WAS 2014, WHO 2015). Acknowledging that sexuality, sexual health, and sexual rights are part of human rights compels people to guard, defend, uphold, and advocate for freedom to enjoy and express their sexuality.

Regarding sexuality, the American Psychological Association (APA 2017) has championed rights for sexual and gender minorities for over four decades. For example, in 1975 APA advocated to remove stigma associated with gay, lesbian, and bisexual orientations, adopted The Guidelines for Psychological Practice with Lesbian, Gay and Bisexual Clients in 2000, and established the Virtual Working Group on Restrictions Affecting Diversity Training in Graduate Education in 2011. There are numerous policy statements on the rights of sexual and gender minorities (available at https://www.apa.org/pi/lgbt/resources/poli cy) and APA has the Office on Sexual Orientation and Gender Diversity.

While APA and other psychological associations have focused on nondiscrimination and non-violence for sexual minorities, there needs to be more training on sexuality overall. They have not focused on sexuality enough in their training for clinicians to feel comfortable discussing all aspects of sexuality with their clients, including sexual pleasure (Dermer and Bachenberg 2015, Tolman and Diamond 2014). Research has repeatedly demonstrated clinicians do not get adequate training in sexuality and are not comfortable discussing sexuality when they do discuss sexuality (Burnes et al. 2017, Hanzlik and Gaubatz 2012, Kelsey et al. 2011, Miller and Byers 2008, Miller and Byers 2009, Miller and Byers 2012, Mollen et al. 2018). Therapists and psychologists are required to understand basic sexual development and are not supposed to discriminate against sexual minorities.

Both the APA's Code of Conduct (APA 2017), the APA's most recent strategic plan (APA 2019), and the European Federation of Psychologists' Associations (EFPA) policy on Human Rights and Psychology (accepted by the General Assembly of EFPA in July 2015) discuss psychologists' respect and protection of human rights. Yet, there is scant literature on training psychologists in a human rights perspective (see Patel 2019, 2020 for a discussion of human rights and applied psychology), and no literature in training psychologists in sexuality from a human rights perspective. Psychology has advocated for sexual minorities in their training, code of ethics, and political discourse, but has done so from a diversity and social justice perspective, rather than a human rights perspective. Adding a human rights perspective to teach about sexuality, sexual 
health and wellness, and sexual rights may provide a pedagogical framework that has advantages over multicultural and social justice perspectives. The definition of human rights, a review of sexual rights as human rights, and an examination of how a human rights perspective can be used to train clinicians will be presented.

\section{Human Rights}

Human Rights are basic freedoms and rights inherent to all human beings and supersede social, political, and cultural values and norms (United Nations Population Fund [UNFPA] 2014). The Universal Declaration of Human Rights (UDHR) was adopted by the United Nations General Assembly in 1948 and was created in an effort to prevent many of the atrocities of World War II (Patel 2019). This extraordinary document was meant to recognize the incontrovertible dignity and inalienable rights of all human beings, and is based on the ideas of freedom, justice, and peace (Patel 2019).The General Assembly, which created the UDHR, is the main policymaking arm of the United Nations (UN) and all Member States have representation in the General Assembly. Given the global representation in creating the UDHR and focus on all humankind, it is expected that governments and other political, social, legal, and educational systems have the duty to respect, protect, and advocate for human rights in a context of equality, non-discrimination, inclusion, and accountability (UNFPA 2014).

\section{Sexual Rights as Human Rights}

Compared to exploration of other rights, sexual rights are still relatively new in the human rights discourse (Parker 2007). In the public health sector, the inclusion of sexual wellness with the right to health was recognized as early as 1975 in a WHO Technical Report series (WHO 1975). In addition, the WAS, the WHO, the Sexual Rights Initiative (SRI), the Pan American Health Organization (PAHO) the International Planned Parenthood Federation (IPPF), and other international organizations have been involved in promoting healthy sexuality and examining the importance of conceptualizing sexual rights as human rights. The SRI (2016) believes that it is the responsibility of every government to respect, protect, and fulfill human rights - including sexual rights. The WAS stated categorically that "sexual rights are human rights" (Kismödi et al. 2017: 1).

Sexual rights are universal human rights based on the inherent freedom, dignity, and equality of all human beings. Since health is a fundamental human right, so must sexual health be a basic human right. In order to assure that human beings and societies develop healthy sexuality, the following sexual rights must be recognized, promoted, respected, and defended by all societies through all means. Sexual health is the result of an environment that recognizes, respects and exercises these sexual rights (WAS 2014). 
The IPPF (2008) has also declared sexual rights as a part of Human Rights in their document, Sexual Rights: an IPPF Declaration. They are committed to a human rights approach that includes sexuality. “...sexual rights are a component of human rights, which are an evolving set of entitlements related to sexuality that contribute to the freedom, equality and dignity of all people" (IPPF 2008: 10). Their declaration includes seven guiding principles and ten sexual rights. These principles and rights recognize sexuality as an integral part of personhood, nondiscrimination and freedom from harm, the right to sexual pleasure for everyone, and limitations on sexuality should be few and when needed should be for the greater good, to protect other people's rights, and non-discriminatory.

All of these organizations believe recognizing sexual rights as human rights is an important step in improving the sexual wellbeing and health of people across the world (Kismödi et al. 2017). The inclusion of sexual rights as human rights is important because a human rights perspective compels people to guard, defend, uphold, and advocate for people's freedom to enjoy and express their sexuality (Kismödi et al. 2017). Human rights emphasize that each person is entitled to equal rights as a citizen of their country and as a global citizen (a member of the interconnected world).

The discourse about sexual rights has included the concept of sexual citizenship (Evans 1993, Richardson 1998, Richardson 2017, Richardson 2018). It includes the idea that people have a sexual contract with their governments, carried out through policies and laws, as a member of that nation (Richardson 2017). Writing from a public health and human rights perspective, Parker (2007) envisioned "sexual citizenship" as "only possible when all people have the right to pursue a satisfying, safe, and pleasurable sexual life" (973). The concept of sexual citizenship emphasizes how sexual rights can be granted or restricted by governments and the fight for formal equality should be at the level of national and global citizenship (Richardson 2000, 2018).

There is some criticism of utilizing a human rights perspective. For instance, Fabeni and Miller (2007) point to possible problems with including sexual rights under the right to health, including a history of political, legal, medical, and behavioral institutions medicalizing sexuality and limiting sexual rights to only those that directly relate to physical health. However, more recent views of health focus on wellness in a physical, mental, spiritual, and sexual sense. Furthermore, adopting a sex positivity framework to help ensure sexual rights provides a path for not just focusing on freedom "from," but also freedom "to." Freedom "from" fear is mentioned in the preamble of the UDHR (1948). It means that people should not fear violence and discrimination. Freedom "to" means justly expressing one's rights and is reflected in documents like the United States Declaration of Independence in the right to pursue happiness - the right to pursue wellbeing in a way that fulfills people without violating the rights of others. In this vein, the sex positivity model focuses on sexual wellness (Cruz et al. 2017, Dermer et al. 2019). Those working from a sex positivity model highlight non-pathological aspects of sexuality, informed consent, sexual pleasure, eroticism, open sexual communication, and freedom of sexual and gender expression (Burnes et al. 2017, Cruz et al. 2017, Dermer et al. 2019, Glickman 2000). Despite possible pitfalls, a human rights 
perspective to sexuality provides a viable and interesting alternative to medical, diversity, and social justice perspectives typically used to teach about sexuality.

\section{Psychology Training and Sexuality}

Psychologists and therapists are trained in diagnosing sexual dysfunction, trained in their ethical obligations against discrimination, and expected to advocate for sexual minorities. Overall, applied psychology programs seem to train more about sexual orientation and related discrimination rather than sexual health and wellness (Burnes et al. 2017, Mollen et al. 2018). Both diversity and social justice frameworks are used to train psychologists and therapists about discrimination, violence, and oppression related to sexual and gender orientation and the intersection between a sexual minority status and other identities.

\section{Multicultural and Social Justice Perspectives}

Multiculturalism and social justice, while different in their approach to education and therapy in some ways, also share many commonalities. Both perspectives acknowledge the importance of diversity and recognize that oppression has a debilitating effect on mental health (Ratts 2011). They also both promote the need to develop multicultural and advocacy competent helping professionals, interventions that are culturally sensitive, and emphasize understanding the oppressive status quo. These approaches also have their differences. The development of multicultural and social justice competencies across mental health fields has exemplified the commitment to social change and remedying social injustice by assisting various mental health professionals to understand individuals', couples', families', and institutions' circumstances and concerns from a more ecological perspective (Constantine et al. 2007). Some authors believe that multiculturalism and social justice are synergic (Prilleltensky and Prilleltensky 2003). In reality, both perspectives are probably used in most training programs even if one is more emphasized.

Although it is not intended to go into an in-depth review of the history, development, or nuances of each approach, some basic differences will be presented in order to later discuss the advantages of using a human rights perspective to teach about sexuality. Multiculturalism focuses on gaining knowledge of various cultural identities and on sensitivity to issues of bias, discrimination, and oppression without ranking or comparing groups nor necessarily challenging contradictory perspectives between groups (Vera and Speight 2003). As multiculturalism pertains to the therapeutic relationship, it involves understanding cross-cultural relationships and developing awareness, knowledge, and skills as they relate to the ability to work in a diverse society (Pieterse 2009). Social justice, rather than focusing on knowledge of differences and how they might influence the therapeutic relationship, highlights how some groups are more or less privileged in society (Vera and Speight 2003). Social justice involves the intentional awareness of systemic forces of oppression that 
includes a political component and speaks to an active engagement in redressing social inequities while aiming to provide full and equal participation by all groups. The central focus of social justice is to respond to systemic inequalities that serve to marginalize and disenfranchise various groups of people and should be designed to change social values, structures, policies, and practices that affect disadvantaged or marginalized groups (Pieterse 2009).

Regardless of the perspective, clinicians need to move forward in their approach to addressing sexual health and sexual rights (Prilleltensky and Prilleltensky 2003).The discussion of using multicultural and social justice perspectives was somewhat simplified, but the basic point was that they are not comprehensive enough to be the only frameworks used to discuss sexuality. When only these perspectives are used, the discussions are skewed toward only the freedom from bias, discrimination, violence, barriers, and oppression rather than also including a sexual health and sexual wellbeing perspective.

\section{Utilizing a Human Rights Perspective to Teach Sexuality}

The basis of seeing sexuality and sexual rights, not just reproduction, as part of human rights is because it is conceptualized as part of a holistic, comprehensive view of health. Besides sexual and gender orientation and their expression, sexuality can include eroticism, sexual pleasure, body image, masturbation, sexual behaviors/fanstasies, sexual functioning, reproduction and reproductive health, attachment, intimacy, sexual knowledge and communication (and informed consent), and spirituality (Mollen et al. 2018, Robinson et al. 2002).

Sexual health is an approach to sexuality founded in accurate knowledge, personal awareness and self-acceptance, such that one's behavior, values and emotions are congruent and integrated within a person's wider personality structure and selfdefinition. Sexual health involves an ability to be intimate with a partner, to communicate explicitly about sexual needs and desires, to be sexually functional (to have desire, become aroused, and obtain sexual fulfillment), to act intentionally and responsibly, and to set appropriate sexual boundaries. Sexual health has a communal aspect, reflecting not only self-acceptance and respect, but also respect and appreciation for individual differences and diversity, as well as a feeling of belonging to and involvement in one's sexual culture(s). Sexual health includes a sense of selfesteem, personal attractiveness and competence, as well as freedom from sexual dysfunction, sexually transmitted diseases, and sexual assault and coercion. Sexual health affirms sexuality as a positive force, enhancing other dimensions of one's life (Robinson et al. 2002: 45).

A literature search produced no articles on using a human rights perspective to train psychologists and therapists in sexuality. There have been several studies, though, that point to the lack of comprehensive sexuality training for clinicians (Mollen et al. 2018). Despite the importance of sexuality to every human across their lifespan, neither educators (Swislow 2016) nor students feel adequately prepared to talk about sexuality in-depth.

Some clinical and counseling psychology programs include a course on sexual dysfunction or sex therapy, but usually they are offered as topics in other 
courses or as an elective (Swislow 2016). In Mollen et al.'s (2018) recent survey of Canadian and U.S. doctoral counseling psychology programs, they found that $94.7 \%$ of programs provided training on sexual and/or gender orientation, $76.3 \%$ had some training on sexual intimacy skills and intimate relationships, $15.8 \%$ reported included sexual pleasure, and $39.5 \%$ of respondent programs reported training in sexual functioning and behavior. Although $47.5 \%$ of respondents reported addressing sexual health, topics under this area seemed more related to sexual trauma and exploitation rather than focusing on positive aspects wellbeing. Finally, few of the programs reviewed different forms of sexual expression: sex toys $(5.3 \%)$, pornography $(7.9 \%)$, kink $(15.8 \%)$, BDSM (15.8\%), swinging $(5.3 \%)$. Finally, the majority of respondents $(78.9 \%)$ thought training in sexuality was important even though they did not think they have time to include more about sexuality and/or there were obstacles to providing more information about sexuality.

A human rights framework to sexuality would address many of the same issues as multicultural and social justice perspectives on a global level in addition to health and wellness as related to sexuality. "The term human rights framework refers broadly to human rights responsibilities, commitments, and principles, which are based in international human rights law" (Patel 2019: 114). Both a human rights perspective and applied psychology share a focus on health and wellbeing (Patel 2019). Using a human rights perspective forces psychology to look at the cause and context of sexual rights violations, not just the outcome and associated symptoms. Some principles that a human rights perspective on sexual rights and psychology share concerns about are: fairness, respect, dignity, autonomy, participation and inclusion, proportionality (of restriction of rights), equality, and non-discrimination (Patel 2019). Among other responsibilities related to human rights, psychologists have an obligation to understand, monitor, and research sexuality, sexual health, and sexual rights, and apply that knowledge to their work, institutions, and advocacy. Part of human rights is "right to the highest attainable standard of health with regards to sexuality and sexual health" (Kismödi et al. 2017: 21). This also includes the right to benefits of scientific progress and its application and the right to education on sexuality and sexual health.

A human rights approach can also contend with "conscience clauses" which allow for refusing to work with certain clients based on free speech and/or freedom of religion. One of the major obstacles to training in sexuality, besides the lack of comfort discussing sexual issues, has been religious and cultural objections to certain sexual acts, behaviors, and sexual and gender orientations. Accrediting bodies, governments, agencies, and professionals sometimes circumvent discussions of sexuality and limit sexual rights on the basis of morals (Kismödi et al. 2017). For mental health professionals, framing sexual and gender issues as diversity issues led to some progress in training professionals and serving clients, but it has also caused some problems. From a multicultural perspective, one set of authentically held cultural beliefs does not "trump" another set of authentically held cultural beliefs. 
In the past, some of the accrediting bodies and codes of ethics left some room for refusing to serve SGM clients on the basis of a "conscience clause". The current ethical standards of major accrediting and professional organizations of mental health organizations have closed that gap by expecting members of their organizations to get the training and supervision needed to work with all clients regardless of their sexual or gender orientations. In contradiction to professional ethical standards, several states in the U.S. have introduced conscience clauses that would allow students and professionals to refuse to provide services to clients if the clients' goals contradict the professional's religious beliefs. For example, in 2011 Arizona passed into law a Bill that allows trainees to refuse to see certain clients (Wise and Bieschke 2015). The American Psychological Association (APA 2017) has been at the forefront of protecting the ethical and accreditation standards requiring trainees be trained to work with diverse clientele, including LGBTQI+ clients. In the Fall of 2011 they established the Virtual Working Group on Restrictions Affecting Diversity Training in Graduate Education. The APA (2017) working group created five core tenants of training for APA: (a) Psychology has a compelling interest in meeting the needs of a diverse client population; (b) trainers are responsible for education and training; (c) trainers respect trainees' developmental process and foster cognitive complexity; (d) attaining competence to work with a diverse public is not optional.

Although APA's position is strong about the requirement to learn how to work with diverse clientele and serve diverse clientele, a human rights approach would help solidify that position. When teaching from a multicultural framework it is difficult to argue why one group's values and beliefs supersede another group's needs. When teaching from a human and sexual rights perspective, these rights are framed as basic freedoms and rights and take a meta-position to specific cultural and religious beliefs. A human rights approach means taking action to change cultural ideas and practices if they violate these fundamental rights.

\section{Conclusion}

The human rights perspective, applied to the realm of sexuality, although not without faults, has many of the advantages of multicultural and social justice frameworks with the added emphasis on sexual health, sexual wellness and sexual rights that should be afforded to all humankind. Educators training clinicians have the difficult task of helping trainees find a way to act ethically and justly toward the diverse issues they will face and the diverse clientele they will serve while balancing their cultural, personal, or religious belief systems (Wise and Bieschke 2015). Irrespective of individual beliefs, when people become psychologists and therapists they agree to be professionals who are well versed in sexuality, sexual health, and the accompanying rights.

Sexuality is a core aspect of being human, of human development, and of many intimate relationships regardless of one's particular sexual wants, desires, behaviors, sexual orientation, or gender orientation. The global attention to sexual rights and the advocacy of global groups for sexual rights tend to be based on a human rights 
perspective and could offer psychology an additional and powerful way to prepare clinicians, researchers, and educators to be aware of and support sexual citizenship. All humans have the right to live in a world where they enjoy the freedom to experience their sexuality in any way they wish without violating the basic rights of others.

\section{References}

American Psychological Association (2017) Ethical principles of psychologists and code of conduct. Retrieved from https://www.apa.org/ethics/code/. [Accessed 1 May 2020].

Burnes TR, Singh AA, Witherspoon RG (2017) Graduate counseling psychology training in sex and sexuality: An exploratory analysis. The Counseling Psychologist 45(4): 504-527. https://doi.org/10.1177/0011000017714765.

Constatine, MG, Hage S, Kindaichi, MM (2007) Social justice and multicultural issues: Implications for the practice and training of counselors and counseling psychologists. Journal of Counseling \& Development 85(1): 24-29. doi: 10.1002/j.1556-6678.2007. tb00440.x

Cruz, C, Greenwald, E, Sandhil, R (2017) Let's talk about sex: Integrating sex positivity in counseling psychology practice. Counseling Psychologist 45(4): 547-569. doi: 10.11 77/0011000017714763.

Dermer S, Bachenberg M (2015) The importance of training marital, couple, and family therapists in sexual health. Australian and New Zealand Journal of Family Therapy 6(4): 492-503. https://doi.org/10.1002/anzf.1122

Dermer SB, Cipra A, Mercer ME (2019) Exploring the definition and implications of sex positivity for counseling. Unpublished manuscript submitted for publication.

Evans D (1993) Sexual Citizenship: The Material Construction of Sexualities. London: Routledge.

Fabeni S, Miller AM (2007) 'The importance of being perverse: Troubling law, identities, health and rights in search of global justice', In Meyer IH and Northridge ME (eds.) The Health of Sexual Minorities (93-129). Boston: Springer, https://doi.org/10.1007/ 978-0-387-31334-4_5.

General Assembly of the United Nations (2019) About the General Assembly of the United Nations. Retrieved from https://www.un.org/en/sections/about-un/main-organs/. [Accessed 8 July 2019].

Glickman C (2000) The language of sex-positivity. Electronic Journal of Human Sexuality 3. Retrieved from http://www.ejhs.org/volume3/sexpositive.htm. [Accessed 3 November 2018].

Hanzlik MP, Gaubatz M (2012) Clinical PsyD Trainees' Comfort Discussing Sexual Issues with Clients. American Journal of Sexuality Education 7(3): 219-236. https://doi.org/ 10.1080/15546128.2012.707080

International Planned Parenthood Federation (2008). Sexual rights: an IPPF declaration. Retrieved from https://bit.ly/2ET9hZb. [Accessed 1 September 2020].

Kelsey K, Stiles BL, Spiller L, Diekhoff GM (2011) Assessment of therapists' attitudes towards BDSM. Journal of Psychology \& Sexuality 4(3): 255-267. https://doi.org/ 10.1080/19419899.2012.655255.

Kismödi E, Corona E, Maticka-Tyndale E, Rubio- Aurioles E, Coleman E (2017) Sexual Rights as Human Rights: A Guide for the WAS Declaration of Sexual Rights. International Journal of Sexual Health 29(1): 1-92. 
Miller SA, Byers ES (2008) An exploratory examination of the sexual intervention selfefficacy of clinical psychology graduate students. Training and Education in Professional Psychology 2: 137-144.

Miller SA, Byers ES (2009) Psychologists' Continuing Education and Training in Sexuality. Journal of Sex \& Marital Therapy 35(3): 206-219. doi: 10.1080/00926230 802716336.

Miller SA, Byers ES (2012) Practicing psychologists' sexual intervention self-efficacy and willingness to treat sexual issues. Archives of Sexual Behavior 41: 1041-1050. doi 10.1007/s10508-011-9877-3.

Miller AM, Kismödi E, Cottingham J, Gruskin S (2015) Sexual rights as human rights: a guide to authoritative sources and principles for applying human rights to sexuality and sexual health, Reproductive Health Matters 23:46, 16-30. doi: 10.1016/j.rhm.20 15.11.007

Mollen D, Burnes T, Lee S, Abbott DM (2018) Sexuality training in counseling psychology. Counseling Psychology Quarterly: 1-18. https://doi.org/10.1080/095150 70.2018 .1553146

Parker RG (2007) Sexuality, health, and human rights. American Journal of Public Health 97(6): 972-973. https://doi.org/10.2105/AJPH.2007.113365.

Patel N (2020) 'Critical human rights-based approach to applied psychology: Context and power'. In Hagenaars, P, Plavšić, M, Sveaass, N, Wagner, U, Wainwright, T (eds.) Human Rights Education for Psychologists, 61-76. London: Routledge.

Patel N (2019) Human rights-based approach to applied psychology. European Psychologist 24: 113-124.

Pieterse A, Evans S, Risner-Butner A, Collins N, Mason L (2009) Multicultural competence and social justice training in counseling psychology and counselor education. The Counseling Psychologist 37(1): 93-115.

Prilleltensky I, Prilleltensky O (2003) Synergies for wellness and liberation in counseling psychology. The Counseling Psychologist 31(3): 273-281.

Richardson D (1998) Sexuality and citizenship. Sociology 32(1): 83-100.

Richardson D (2000) Rethinking Sexuality. London: SAGE.

Richardson D (2017) Rethinking Sexual Citizenship. Sociology 51(2): 208-224.

Richardson D (2018) Sexuality and citizenship. Sexualities 21(8): 1256-1260. https://doi. org/10.1177/1363460718770450.

Robinson BBE, Bockting WO, Rosser BRS, Miner M, Coleman E (2002) The Sexual health Model: application of a sexological approach to HIV prevention. Health Education Research 17(1): 43-57. https://doi.org/10.1093/her/17.1.43

Ratts MJ (2011) Multiculturalism and social justice: Two sides of the same coin. Journal of Multicultural Counseling and Development 39: 24-37. doi:10.1002/j.2161-1912. 2011.tb00137.x

Sexual Rights Initiative (2016) Advancing sexual rights for all. Retrieved from https://sexu alrightsinitiative.com/resources/advancing-sexual-rights-all. [Accessed 10 May 2019].

Swislow E (2016) Preparedness of doctoral clinical psychology program faculty to integrate topics of human sexuality into academic training. $\mathrm{PhD}$ Thesis, The Chicago School of Psychology, US.

Tolman DL, Diamond LM (2014) Sexuality theory: A review, a revision and a recommendation' In DL Tolman, LM Diamond, JA Bauermeister, WH George, JG Pfaus, and LM Ward (Eds.), APA Handbook of Sexuality and Psychology, vol 1. Person-based Approaches, 3-27. https://doi.org/10.1037/14193-001

United Nations (1948) Universal declaration of human rights. Retrieved from https://bit.ly /30uS53Y. [Accessed 12 February 2019]. 
United Nations Population Fund (2014) UNFPA Annual Report 2013: Realizing the Potential. Retrieved from https://bit.ly/2GbvrGZ. [Accessed 1 September 2020].

Vera EM, Speight SL (2003) Multicultural competence, social justice, and counseling psychology: Expanding our roles. The Counseling Psychologist 31(3): 253-272. https://doi.org/10.1177/0011000003031003001.

Wise EH, Bieschke KJ (2015) Psychology's proactive approach to conscience clause court cases and legislation. Training and Education in Professional Psychology 9(4): 259268. doi: 10.1037/tep0000092.

World Association for Sexual Health (2014) Declaration of Sexual Rights. Retrieved from https://bit.ly/33mX312. [Accessed 7 September 2020].

World Health Organization (1975) Education and treatment in human sexuality: The training of health professionals. Report of a WHO meeting [held in Geneva February 1974]. Retrieved from https://bit.ly/3cP7EZ0. [Accessed May 2019].

World Health Organization (2015) Sexual health, human rights and the law. Retrieved from https://bit.ly/2SimvC3. [Accessed 7 September 2020]. 
